\title{
Ideias agroecológicas: visões e traduções de atores locais no Estado do Pará
}

\section{Agroecological ideas: views and translations of local actors in the State of Pará}

Valdir da Cruz Rodrigues - Doutorando do Programa de Pós-Graduação em Agriculturas Amazônicas (PPGAA) da Universidade Federal do Pará (UFPA). E-mail: valdir. territorio@gmail.com

Marc Piraux - Doutor em Agro-economia na Faculté des Sciences Agronomiques de Gembloux (FUSAGX), Bélgica. Professor da Universidade Federal do Pará (UFPA). E-mail: marc.piraux@cirad.com

\section{Resumo}

Este artigo analisa as "ideias agroecológicas", quer dizer, a dimensão cognitiva dos atores sociais - instituições da sociedade civil e do poder público - de três territórios no Estado do Pará. Analisamos, assim, o referencial, as visões que eles defendem com relação à agroecologia e como esse referencial influência ações em favor da agricultura familiar. A partir da interlocução, junto a atores sociais implicados em agroecologia, procedeu-se com análises comparativas entre diferentes ideias, de diferentes atores. A lógica das visões de cada ator social é fruto dos objetivos de cada instituição, e do contexto territorial onde ela atua. $\mathrm{O}$ território, como suas especificidades, molda as visões dos atores e das instituições.

\begin{abstract}
This article analyzes the "agroecological ideas", that is, the cognitive dimension of social actors - institutions of civil society and public power - in three territories in the State of Pará. to agroecology and how this reference influences actions in favor of family farming. From the dialogue with social actors involved in agroecology, we proceeded with comparative analyzes between different ideas of different actors. The logic of the visions of each social actor is the result of the objectives of each institution and the territorial context in which it operates. The territory, like its specificities, shapes the views of actors and institutions.
\end{abstract}

\section{Palavras-chave}

Agroecologia. Territórios. Atores sociais. Agricultura familiar.

\section{Keywords}

Agroecology. Territories. Social actors. Family farming. 


\section{INTRODUÇÃO}

Cada vez mais, os estudos acerca da agroecologia apontam para sua apresentação com perfil polissêmico. A multiplicidade de atores que incorporaram essa característica em suas diretrizes e práticas tem se acentuado (BRANDENBURG; LAMINE; DAROLT, 2013). Nessa perspectiva, a agroecologia - como ciência, prática e movimento social (TOLEDO, 2016) propõe uma abordagem transdisciplinar. Essa polissemia se expressa como ciência em Sistemas Agroflorestais (SAFs), por exemplo, onde se evidencia a importância dos saberes locais na coconstrução de conhecimentos; como prática, por conta de variados tipos de contextos ecológicos, econômicos e sociais em diferentes realidades; e como movimento social, em que se expressam contextos políticos e suas diferentes dinâmicas. Nesse sentido, a agroecologia se configura de forma cada vez mais acentuada, como diretriz de políticas governamentais e como parte do sistema de educação formal. Esses três componentes (ciência, prática e movimento) apresentam grandes variações e retratam, justamente, visões de múltiplos atores acerca da agroecologia.

Esse caráter polissêmico traduz o conceito chave que o guia: a sustentabilidade, evidenciando uma agroecologia como manejo ecológico dos recursos naturais, por meio da ação coletiva (GUSMÁN, 2002). Aqui, muitos autores devolvem a inovação local como dispositivo metodológico, necessário para a criação de ambientes de interação entre agricultores e acadêmicos (PETERSEN; DAL SOGLIO; CAPORAL, 2009). Nessa perspectiva, a agroecologia vai além de considerações técnicas, expressando-se no universo social, cultural, ambiental e econômico, além de manifestar interesses pelas condições e capacidades de fortalecimento da agricultura camponesa (PIRAUX et al., 2012). Expressa-se um potencial endógeno que, por meio da articulação do saber local com o conhecimento científico, permite a implementação de sistemas de agricultura alternativa capazes de fortalecer a biodiversidade ecológica e a diversidade sociocultural (CAPORAL; COSTABEBER, 2004).

Como estratégia de desenvolvimento rural, a perspectiva agroecológica supõe a realização de processos de distribuição e segurança alimentar, que envolvem produção, elaboração, transformação, transporte, distribuição, conservação e preparação de alimentos (MOLINA, 2011). Esse processo se traduz no sentido de rede e de inovação socioterritorial, uma vez que a agroecologia, por si, é uma construção social em rede, e as iniciativas agroecológicas só ganham densidade social quando articulam vários atores que assumem papéis complementares na construção dos sistemas agroalimentares (PETERSEN, 2018; PIRAUX et al., 
2012). Da mesma forma, a atuação em rede promove a capacidade de perceber, nas práticas cooperativistas e solidárias, variadas possibilidades de valorização de valores humanos e éticos, que orientam as competências privadas ou fatos culturais (SABOURIN, 2006).

O papel político atribuído à agroecologia tem emergido, assim, como resultado da diversidade das realidades e nos desafios cotidianos que se apresentam. Essa perspectiva pode ser entendida como análise e atuação sobre as condições sociais, as redes e os conflitos. Trata-se de uma problematização política dos conflitos sociais e ambientais, associados ao manejo de recursos naturais e à construção de sistemas agroalimentares sustentáveis, capazes de assegurar as necessidades básicas das populações (COLLADO; GALLAR, 2010). Isso pode ser observado, inclusive, em trajetórias territoriais que expressam lógicas de construção de ideias e de práticas agroecológicas resultantes da intervenção de variados atores sociais e em diferentes espaços e tempos. Os debates e as práticas, em perspectiva agroecológica, ocorrem no âmbito dos territórios, cuja significação se expressa numa relação de poder que precisa ser constantemente debatida (FERNANDES, 2006).

No caso deste artigo, verifica-se que esses contextos territoriais influenciam o tipo de agroecologia construído no âmbito deles. Pensamos que, de fato, a densidade de mobilização de atores coletivos e processos de politização dos movimentos por ele capitaneados (ABRAMOVAY; BEDUSCHI FILHO, 2004; HAESBAERT, 2006; RAFFESTIN, 1993) vão influir o tipo de agroecologia defendido e implementado. A segunda hipótese, é que a noção de território, fundamental para a agroecologia, é mais ou menos apropriada pelos atores e instituições locais, influenciando no referencial de agroecologia. Pode-se relacionar a agroecologia ao próprio processo de desenvolvimento territorial, que se constitui um processo de mudança estrutural empreendido por uma sociedade organizada territorialmente, sustentada na potencialização dos capitais e recursos (materiais e imateriais), capaz de dinamizar a economia e a melhorar a qualidade de vida da sua população (DALLABRIDA, 2010).

Para testar essas hipóteses, desenvolvemos estudos no Estado do Pará, onde diferentes experiências agroecológicas têm sido implementadas durante a última década. Essas dinâmicas têm ocorrido em territórios de ação coletiva e em territórios específicos de ação pública. Entre outros, os territórios de ação pública receberam as contribuições do Programa Nacional de Desenvolvimento Sustentável dos Territórios (PRONAT) e do Programa Territórios da Cidadania (PTC) do governo federal. Isso se deu através da política de desenvolvimento territorial do Ministério 
do Desenvolvimento Agrário (MDA), executada no país no período de 2004 a 2016. No Pará, esses territórios construíram trajetórias distintas.

Assim, este texto tem como espaço de análise os territórios do Baixo Tocantins, do Nordeste Paraense e do Sudeste Paraense e seus principais atores - as instituições sociais, econômicas, ambientais, culturais da sociedade civil e do poder público. Analisa-se as ideias em torno do referencial da agroecologia mobilizado pelos atores nesses três territórios, sendo que se optou por esses por se considerar suas importantes diferenças: no Nordeste Paraense, a agroecologia já foi implantada e possui muitas experiências em curso num contexto de uma antiga colonização. O território possui muitas referências de produção diversificada na agricultura familiar. No Baixo Tocantins, as Organizações Não Governamentais (ONGs) atuam muito em favor da agroecologia em um contexto da Amazônia das ilhas, e o surgimento de redes consolidou uma agroecologia que se fortaleceu mesmo após o encerramento da política territorial do governo federal, em 2016. No Sudeste Paraense, a atuação das instituições de ensino e pesquisa e dos movimentos sociais foi fundamental para o fortalecimento da agricultura familiar num contexto de conflitos agrários fortes.

Não se trata aqui de analisar o jogo dos atores ao nível do Colegiado de Desenvolvimento Territorial (Codeter) ${ }^{1}$, que explicaria qual é a visão que foi privilegiada ao nível de cada território, orientando as estratégias. Esse será o objetivo de outro artigo. Trata-se da análise das "ideias agroecológicas", no sentido de compreender o referencial cognitivo, as visões, percepções e crenças que eles defendem com relação à agroecologia, e que orientam, então, as ações dos atores sociais. Esse conceito resulta da teoria dos 3 I (ideias, interesses e institucionalização) (PALIER; SUREL, 2005), que foi usada para analisar a lógica dessa ação pública nos territórios.

Foram realizadas 38 entrevistas - entre 2017 e 2018 - com representantes de instituições do poder público e da sociedade civil envolvidos com o tema da agroecologia, e que faziam parte ou não do território institucional (Codeter). Alguns eram membros das coordenações dos colegiados e outros eram representantes de instituições que não estavam nos Codeter, mas cuja atuação no território era importante para a agroecologia. Além disso, ocorreu a participação em atividades locais (reuniões, feiras agroecológicas, seminários e dias de campo).

Além dessa introdução, o artigo organiza-se em outras duas partes. No próximo, são apresentados os contextos territoriais e os atores mobilizados

Instância coletiva de gestão social, organizada em cada território, composta por representantes de instituições da sociedade civil e do poder público atuantes nos territórios, com poder para deliberar sobre as ações territoriais. 
em torno da agroecologia. Posteriormente, trata-se das ideias expressas pelos diferentes atores sociais (as instituições) acerca da agroecologia, identificadas em cada um dos três territórios. Ao final, conclui-se com as considerações finais.

\section{OS CONTEXTOS TERRITORIAIS E OS ATORES IMPLICADOS NA AGROECOLOGIA}

Esta parte do trabalho objetiva analisar o contexto territorial, para entender melhor a emergência das ideias e as diferenças entre os três territórios.

\subsection{TRAJETÓRIA E BREVE CONTEXTO DOS TRÊS TERRITÓRIOS}

A Figura 1, a seguir, apresenta o mapa com a localização dos três territórios estudados (Baixo Tocantins, Nordeste Paraense e Sudeste Paraense), situados no contexto de todos os Territórios da Cidadania estabelecidos no Estado do Pará. Figura 1 - Territórios da Cidadania no Estado do Pará

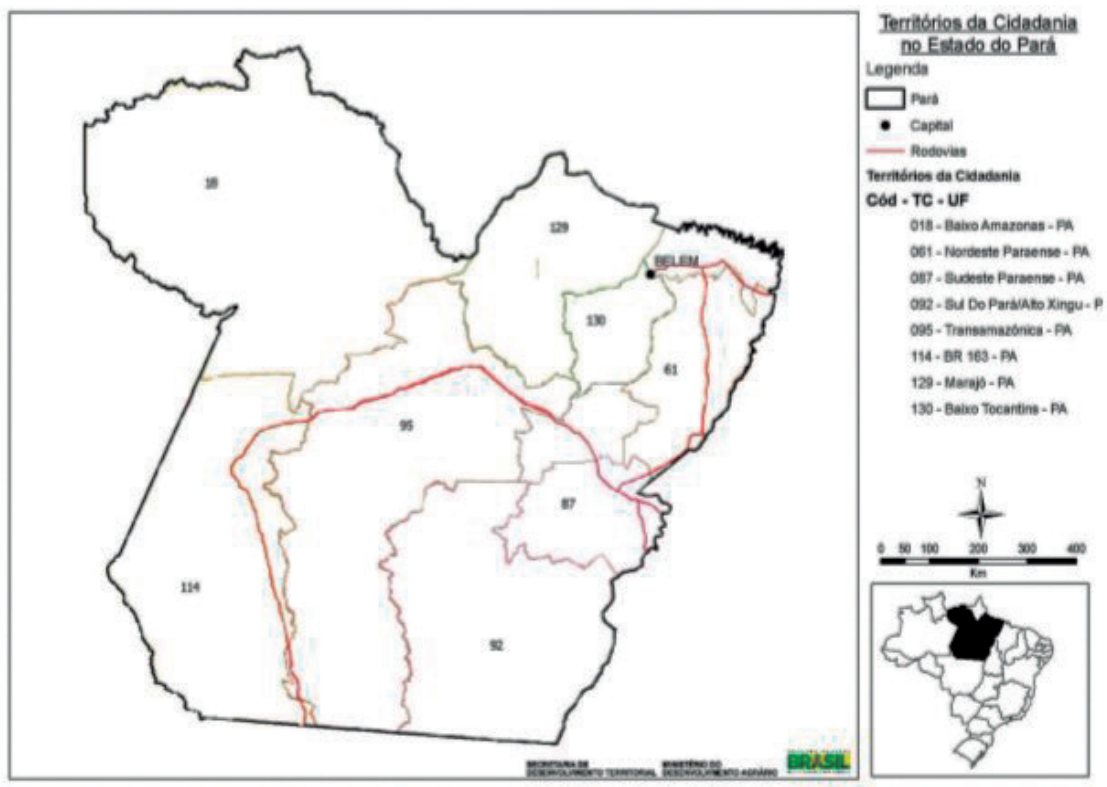

Fonte: Piraux et al. (2012).

Os três territórios foram homologados no contexto da política territorial do MDA, extinto em 2016. Contudo, eles construíram sua trajetória de maneiras diferentes. No que se refere a esses territórios, os caminhos percorridos entre as regiões do estado conduziram a uma diversidade de situações territoriais, que 
poderiam ser resumidas assim: Amazônia dos rios (parte do Baixo Tocantins); frentes pioneiras (uma parte do Baixo Tocantins); e antigas frentes pioneiras consolidadas (COSTA, 2000) (Nordeste e Sudeste Paraense) (PIRAUX et al., 2012).

No Baixo Tocantins, as florestas constituem um dos principais espaços de moradia e subsistência (através do agroextrativismo) das famílias ribeirinhas, ainda que existam áreas de terra firme onde há produção agropecuária. A produção e comercialização de produtos in natura, em especial o açaí (Euterpe oleracea), é um dos principais fatores que impulsionam as economias locais. A trajetória do território é marcada pela forte atuação de organizações da sociedade civil e por importantes mobilizações sociais. A atuação de ONGs, como a Associação Paraense de Apoio às Comunidades Carentes (APACC) e a Federação de Órgãos para Assistência Social e Educacional (Fase), tem propiciado a execução de iniciativas visando alternativas de desenvolvimento sustentável que integrem a conservação de seus recursos naturais, a organização, a produção e a comercialização.

O território Nordeste Paraense faz parte de uma das mais antigas áreas de colonização na Amazônia, pelo menos no norte do território. A origem dos municípios está vinculada às incursões realizadas pelos portugueses ao interior do estado, durante os tempos da colônia. A formação étnica predominante no território tem caracterização indígena e portuguesa, com forte influência da cultura nordestina, tendo em vista o fluxo migratório na década de setenta, a partir da construção da Belém-Brasília (BR-010) e da Pará-Maranhão (BR-316). Os municípios se caracterizam, no aspecto produtivo e econômico, pela geração de renda a partir de grande variedade produtiva. Essa diversidade produtiva, associada à pesquisa e inovação tecnológica, sobretudo através dos Sistemas Agroflorestais (SAFs), são marcas que bem identificam o território com um potencial produtivo da agricultura familiar.

O Sudeste Paraense é um território que se situa numa região de fronteira, cujo processo de ocupação e uso dos recursos do território foram marcados por intensas disputas entre modelos diferentes de desenvolvimento, acarretando em graves conflitos fundiários, ambientais e sociais. Alguns objetivos em comum entre movimentos sociais camponeses e a Universidade Federal do Sul e Sudeste do Pará (Unifesspa) - influenciaram na formação de uma identidade de agricultura familiar nesse território, tais como o fortalecimento de sistemas produtivos, a qualificação técnica de jovens camponeses e o acesso à escolarização superior.

Os processos percorridos pelo Codeter do Sudeste criaram estratégias que resultaram na criação de mecanismos territoriais em favor da agricultura familiar. Um dos principais referenciais das estratégias utilizadas privilegiaram 
a capacitação técnica de profissionais de Assistência Técnica e Extensão Rural (Ater) e de camponeses, além da oferta de educação (formal e informal) em uma região formada por muitos Projetos de Assentamentos (PA) de reforma agrária, de responsabilidade do Instituto Nacional de Colonização e Reforma Agrária (Incra). Dois pilares foram fundantes na trajetória desse território: a) a atuação de movimentos sociais com forte atuação na luta pela posse e permanência na terra; e b) a atuação da Unifesspa, através do ensino e extensão.

\subsection{OS ATORES MOBILIZADOS NA AGROECOLOGIA NOS TRÊS TERRITÓRIOS}

Esta parte do trabalho objetiva fazer uma breve tipologia dos atores (da sociedade civil e do poder público) implicados em agroecologia, destacando suas especificidades em relação aos contextos territoriais.

\subsubsection{Baixo Tocantins}

Nesse território, a presença de instituições da sociedade civil, principalmente ONGs, sindicatos, cooperativas e representações de populações tradicionais locais, possibilitou o fortalecimento do Codeter, demonstrando um comparecimento de instituições da sociedade civil superior às participações do poder público. $\mathrm{O}$ Quadro 1, a seguir, apresenta quatro grupos de atores entrevistados e uma síntese de suas ações relacionadas à agroecologia no território.

Quadro 1 - Atores envolvidos em agroecologia - Território Baixo Tocantins

\begin{tabular}{|c|c|}
\hline $\begin{array}{l}\text { Movimentos Sociais - STTR e Fetagri. } \\
\text { Políticas públicas agroecológicas; } \\
\text { Experiências produtivas diversificadas } \\
\text { locais; } \\
\text { Grupos de mulheres agroextrativistas. }\end{array}$ & $\begin{array}{l}\text { Codesei - Consórcio de Desenvolvimento } \\
\text { do BT - (Prefeituras municipais) } \\
\text { Políticas públicas para secretarias municipais; } \\
\text { Projetos em parceria entre ONGs e } \\
\text { prefeituras }\end{array}$ \\
\hline $\begin{array}{l}\text { UFPA - IFPA } \\
\text { Ensino, pesquisa e extensão; Educação } \\
\text { das florestas e das águas. }\end{array}$ & $\begin{array}{l}\text { ONGs (APACC, Ucodep, Fase) } \\
\text { Grupos produtivos locais; Acesso a mercados; } \\
\text { Grupo de mulheres agroextrativistas; Rede } \\
\text { Jirau de Agroecologia }{ }^{2}\end{array}$ \\
\hline
\end{tabular}

Fonte: elaborado pelos autores com base nos dados da pesquisa (2018).

2 A Rede Jirau teve sua conformação em 2016. Trata-se de uma rede composta por pessoas (agricultores familiares) e por organizações sociais (públicas e da sociedade civil). Possui uma estrutura: 1) Coordenação; 2) Coordenação Ampliada; 3) Comissões de coordenação das feiras agroecológicas; 4) Comissões de organizações de eventos; 5) Grupos nas comunidades; 6) Grupos de trabalho de discussão de políticas públicas, como o PAA e o PNAE. Possui como parceiros: instituições privadas; instituições do poder público, de ciência e tecnologia; e movimentos sociais. 
Esses atores entrevistados desenvolvem diversas atividades visando a promoção da agroecologia, seja no campo da reivindicação, como é o caso dos movimentos sociais (apesar de eles também desenvolverem projetos locais); seja através do ensino, pesquisa e extensão contextualizados (caso da UFPA e do Instituto Federal do Pará-IFPA); seja na assessoria a grupos produtivos locais, caso da ONGs; seja na articulação de projetos para prefeituras, como é o caso do Codesei.

No decorrer do tempo, outros atores sociais importantes foram se inserindo no colegiado, trazendo consigo experiências relacionadas à agroecologia, como é o caso do IFPA. Além de suas ações individuais, esses atores também se mobilizam em torno da realização de feiras agroecológicas regulares em diversos municípios do território e do Jirau Agroecológico, que reúne estudantes, pesquisadores, populações tradicionais e é realizado anualmente desde 2017, coordenado pela Rede Jirau de Agroecologia.

\subsubsection{Nordeste Paraense}

Os atores que foram entrevistados no âmbito desta pesquisa, nesse território, estão organizados no Quadro 2, a seguir:

Quadro 2 - Atores envolvidos em agroecologia - Território Nordeste Paraense

\begin{tabular}{|c|c|}
\hline $\begin{array}{l}\text { Emater, Embrapa e Sebrae (+ a UFPA } \\
\text { e Ufra) } \\
\text { Fortalecimento de SAFs familiares; Ater; } \\
\text { Projetos locais; Arranjos institucionais. }\end{array}$ & $\begin{array}{l}\text { UFPA, Ufra, Ecrama, CFR } \\
\text { Ensino, pesquisa e extensão; Economia } \\
\text { solidária - atuação em rede; Feiras } \\
\text { agroecológicas; Educação do campo. }\end{array}$ \\
\hline $\begin{array}{l}\text { Cooperativa de D' IRITUIA. } \\
\text { Cooperativismo e agroecologia; } \\
\text { Dinamização econômica e acesso a } \\
\text { mercados diversificados. }\end{array}$ & $\begin{array}{l}\text { Movimentos Sociais - Rede Bragantina, } \\
\text { STTR, Fetagri, MST } \\
\text { Políticas públicas agroecológicas; Grupos } \\
\text { e redes socioprodutivas de mulheres; } \\
\text { Experiências produtivas diversificadas } \\
\text { locais; Feiras agroecológicas. }\end{array}$ \\
\hline
\end{tabular}

Fonte: elaborado pelos autores com base nos dados da pesquisa (2018).

As ações dos atores deste território combinam: a) a escolarização técnica, tendo nas universidades federais, nas escolas de alternância e no IFPA seu grande referencial, com forte atuação da UFPA, da Universidade Federal Rural da Amazônia (UFRA), da Escola de Formação para Jovens Agricultores (Ecrama) e de várias Casa Familiar Rural (CRF); b) referenciais técnicos, através do aperfeiçoamento e o acesso às inovações técnicas e produtivas, onde a Empresa de Assistência Técnica e Extensão Rural (Emater), a Empresa Brasileira de 
Pesquisa Agropecuária (Embrapa) e o Serviço de Apoio às Micro e Pequenas Empresas (Sebrae) (mais a UFPA e a UFRA) constituem arranjos institucionais e desenvolvem projetos locais, com destaque para os SAFs; c) no desenvolvimento de reivindicações de políticas e projetos e no fortalecimentos de redes da agricultura familiar, das mulheres e da agroecologia, como é o caso dos movimentos sociais; d) na viabilização de projetos orientados para mercados locais e regionais, onde as cooperativas de Irituia se destacam na dinamização econômica dos produtos agroecológicos, através de um cooperativismo empreendedor que acessa mercados diversificados com produtos dos agricultores familiares.

\subsubsection{Sudeste Paraense}

Os atores sociais do Sudeste Paraense promoveram estratégias que associaram a conquista do saber na academia e o desenvolvimento de experiências socioprodutivas. As ações agroecológicas estão relacionadas, ao longo do tempo, primeiro ao campus local da UFPA (e, desde sua criação, em 2013, à Unifesspa) e às ONGs. Depois, os movimentos sociais ficaram mais presentes e, mais recentemente, o IFPA e as instituições de assessoria e de Assistência Técnica e Extensão Rural (Ater) passaram a atuar na execução de iniciativas agroecológicas. O Quadro 3, a seguir, mostra atores (entrevistados) atuantes na promoção da agroecologia.

Quadro 3 - Atores envolvidos em agroecologia - Território Sudeste Paraense

\begin{tabular}{|l|l|}
\hline $\begin{array}{l}\text { Emater, Rede de Ater } \\
\text { Ater; Experiências agroecológicas locais. } \\
\text { Atuação em rede. }\end{array}$ & $\begin{array}{l}\text { IFPA, Escola Família Agrícola (EFA) } \\
\text { Formação técnica de jovens; Ensino, } \\
\text { pesquisa, extensão; Educação do campo. }\end{array}$ \\
\hline $\begin{array}{l}\text { Comissão Pastoral da Terra (CPT), } \\
\text { ONGs }\end{array}$ & $\begin{array}{l}\text { Unifesspa } \\
\text { Ensino, pesquisa, extensão; Educação } \\
\text { Grupos produtivos locais; Feiras } \\
\text { agroecológicas; } \\
\text { desenvolvimento; Feiras agroecológicas. }\end{array}$ \\
$\begin{array}{l}\text { Movimentos sociais - MST, Fetagri, FETRAF. } \\
\text { Luta pela posse da terra; Educação do campo; Políticas públicas agroecológicas; Feiras } \\
\text { agroecológicas }\end{array}$ \\
\hline
\end{tabular}

Fonte: elaborado pelos autores com base nos dados da pesquisa (2018).

A trajetória desses atores tem origem, principalmente, nas ações das Comunidades Eclesiais de Base (CEBs) e dos sindicatos, e, depois, na Universidade Federal (à época era UFPA, passando depois para a Universidade Federal do Sul e Sudeste do Pará-Unifesspa). A atuação do Centro Agroambiental do Tocantins (CAT) e do Laboratório Sócio Agronômico do Araguaia Tocantins (Lasat) foi fundamental no processo de construção de uma identidade territorial. A criação 
do IFPA, na década de 2000, também pode ser considerada um marco para o fortalecimento da agroecologia.

\section{AS IDEIAS AGROECOLÓGICAS}

A tipologia das ideias agroecológicas, identificadas nos três territórios, possibilitou sua aglutinação em quatro grupos (Gráfico 1), os quais passamos a descrever a seguir, apresentando os atores e seus respectivos territórios: Baixo Tocantins (BT), Nordeste Paraense (Tenepa) e Sudeste Paraense (SUD).

Gráfico 1 - Grupos de ideias agroecológicas

\begin{tabular}{|c|c|}
\hline $\begin{array}{l}\text { Grupo } 1 \text { - Agroecologia ecológica e } \\
\text { produtiva } \\
\text { Emater (SUD); Codesei (BT); Emater } \\
\text { (Tenepa); Fetagri/GTA (Tenepa); } \\
\text { Ufra Capitão Poço (Tenepa); Embrapa } \\
\text { (Tenepa); STTR Limoeiro (BT); CPT } \\
\text { (SUD). }\end{array}$ & $\begin{array}{l}\text { Grupo } 2 \text { - Agroecologia ligada à } \\
\text { educação } \\
\text { IFPA de Cametá (BT); Codeter (BT); } \\
\text { UFPA (BT); Ufra Paragominas e Ecrama } \\
\text { (Tenepa); STTR de Igarapé Miri (BT); } \\
\text { IFPA Marabá (SUD); Codeter (SUD); } \\
\text { Unifesspa (SUD); EFA (SUD). }\end{array}$ \\
\hline $\begin{array}{l}\text { Grupo } 3 \text { - Agroecologia ligada ao } \\
\text { empreendedorismo, cooperativismo e } \\
\text { mercados } \\
\text { Cooperativa D'IRITUIA (Tenepa); a } \\
\text { ONG Extensão Amazônia, a Sedap e Rede } \\
\text { Ater (SUD); e a Semagri de Limoeiro do } \\
\text { Ajuru (BT). }\end{array}$ & $\begin{array}{l}\text { Grupo } 4 \text { - agroecologia como ação } \\
\text { política } \\
\text { ONG APACC; Fase; STTR de Cametá } \\
\text { (BT); MST Estadual; Cepasp (SUD); } \\
\text { MMNEPA e a Rede Bragantina (Tenepa) }\end{array}$ \\
\hline
\end{tabular}

Fonte: elaborado a partir de análise realizada pelos autores (2018).

\subsection{IDEIAS DE UMA AGROECOLOGIA ECOLÓGICA E PRODUTIVA (GRUPO 1)}

Esse grupo é composto pela Emater (SUD); Codesei (BT); Emater (Tenepa); Fetagri/GTA (Tenepa); UFRA, campus Capitão Poço (Tenepa); Embrapa (Tenepa); STTR Limoeiro (BT) e CPT (SUD). Apresenta-se uma visão de agroecologia baseada na estratégia dos SAFs, ou mesmo dos consórcios, como forma de valorizar a propriedade e assegurar a produção diversificada. Esses sistemas são vistos como a forma amazônica da agroecologia, da mesma forma que eles também atribuem o sentido de agroecologia às práticas do agroextrativismo no Baixo Tocantins.

Contando com representações dos três territórios (porém, com predominância do Nordeste Paraense, por conta, sobretudo, da forte atuação da 
Emater, da Embrapa e da UFPA), as instituições desse grupo estabelecem relação direta com ações de Assistência Técnica e Extensão Rural (Ater), destacando sua importância para o avanço das estratégias de fortalecimento da agroecologia entre os agricultores e, destes, com a sociedade em geral. Eles concebem que a Ater é fundamental para o sucesso dos SAFs. Os atores entrevistados expressam a necessidade de projetos coletivos e individuais, como forma de assegurar resultados produtivos em curto prazo.

Em geral, essas instituições convergem com a ideia de que, para que ocorra a construção de agriculturas sustentáveis, é necessário estimular o menor uso possível de insumos externos em suas propriedades. Nesse sentido, a Ufra, Emater, Embrapa (Tenepa), CPT e a Emater (SUD) apostam em capacitações técnicas permanentes junto aos agricultores apoiados. Preconiza-se uma visão de autonomia e segurança alimentar, em que as estratégias produtivas devem estimular a manutenção da capacidade produtiva das propriedades e/ou o uso de recursos renováveis locais (como no caso do extrativismo) de maneira sustentável.

Neste grupo, verticaliza-se a percepção de que é fundamental levar em conta a execução de mecanismos de autogestão e participação comunitária dos agricultores. Por isso, é preciso estimular os trabalhos coletivos familiares; o cooperativismo e o associativismo, desde a produção até a comercialização dos produtos, fortalecendo as organizações sociais representativas dos agricultores (associações, cooperativas, ST'TR etc.).

As ideias agroecológicas têm como referência o respeito à diversidade cultural; a valorização de experiências e conhecimentos locais; o incremento da diversidade biológica; assim como o acesso a mercados (ALTIERI, 2005; GLIESSMAN, 2009). Os atores veem como importante o apoio às atividades produtivas dos agricultores, visando o acesso a mercados, uma vez que, se corretamente executadas as ações em cada propriedade, surgirá a necessidade de mercados para os produtos resultantes dos sistemas produtivos diversificados implantados.

Portanto, essas entidades consideram o aperfeiçoamento e a disseminação de boas práticas tradicionais, já existentes nas propriedades, como caminhos viáveis para garantir a sustentabilidade produtiva da região. Os SAFs se enquadram nessa visão estratégica. Além disso, os atores preconizam a necessidade de experimentar alternativas adaptadas aos sistemas com maior tendência de degradação, utilizando-se de técnicas inovadoras e dos saberes tradicionais para reposição da cobertura vegetal e para a conservação dos ecossistemas naturais ainda existentes. 


\subsection{IDEIAS DE UMA AGROECOLOGIA LIGADA À EDUCAÇÃO (GRUPO 2)}

Neste grupo, aglutina-se o IFPA, campus de Cametá (BT); Codeter (BT); UFPA (BT); UFRA, campus de Paragominas e Ecrama (Tenepa); STTR de Igarapé Miri (BT); IFPA, campus de Marabá (SUD); Codeter (SUD); Unifesspa (SUD); e EFA (SUD). A agroecologia é concebida como ação política que parte da educação (formal e informal) e de outras ações afirmativas na sociedade, que possuam como referência a produção de novos conhecimentos. Nessa perspectiva, a melhoria das práticas produtivas da agricultura familiar se relaciona com uma visão crítica da realidade, que pode ser transformada a partir da combinação entre a ecologia, saberes e a economia.

Esses atores apresentam a agroecologia como um movimento político e uma prática que se contrapõe ao modelo produtivo que privilegia a monocultura e o uso predatório dos recursos naturais. Concebem a perspectiva agroecológica como alternativa para discutir a ciência enquanto disciplina e movimento científico, onde ocorrem diálogos entre as áreas de conhecimento. Portanto, a educação assume um papel fundamental na promoção de princípios do campo agroecológico.

Verifica-se que, apesar de todos eles promoverem suas ideias de agroecologia a partir do mesmo campo de atuação (a educação), os mesmos atores viveram trajetórias diferentes. No BT, as práticas têm sua origem nos projetos de ONGs e, mais recentemente, com a criação dos IFPAs (em 2008) e a expansão dos campi da UFPA na região. Elas se incorporam às próprias dinâmicas de escolarização da região. Ocorre uma inserção qualificada da academia e do IFPA nos debates dos conflitos estabelecidos entre governos, grandes empresas e movimentos sociais acerca dos projetos de desenvolvimento estabelecidos nessa região. As ideias agroecológicas são forjadas numa inter-relação estabelecida entre as experiências dos agricultores e a construção do conhecimento nos espaços de escolarização técnica e superior.

No Nordeste Paraense, a Ecrama (nível fundamental e médio) e a Ufra de Paragominas/Capitão Poço (graduação) promovem importante teoria e prática, a partir da escolarização de filhos de agricultores familiares, na perspectiva agroecológica.

No território institucional do Sudeste Paraense (cujo grupo de análise é composto por importantes instituições de ensino e pesquisa, como o IFPA de Marabá, a Unifesspa e a EFA), constata-se que a relação entre os processos de escolarização de jovens (inicialmente com a Unifesspa e a EFA e, depois, com o IFPA) se destaca no que diz respeito aos outros dois territórios. Nesse território, 
o Lasat/UFPA teve uma contribuição importante para a consolidação dos cursos de ciências agrárias da UFPA no interior do estado. Essa instituição concebeu e coordenou a primeira experiência de ensino médio com ênfase na agroecologia, em parceria com movimentos sociais, cujo dispositivo de Pesquisa-FormaçãoDesenvolvimento (PFD), anteriormente, já possuía sua origem no Programa CAT (Centro Agroambiental do Tocantins).

Com a instalação do IFPA em Marabá, a partir de 2008, esse debate se fortaleceu. Ele se inseriu nas dinâmicas territoriais em curso e ocupou um lugar importante no desenvolvimento territorial. Seu projeto político-pedagógico está comprometido com uma escolarização de base agroecológica e com uma gestão participativa da instituição.

\subsection{IDEIAS DE UMA AGROECOLOGIA LIGADA AO EMPREENDE- DORISMO, COOPERATIVISMO E MERCADOS (GRUPO 3)}

Nesse grupo, situam-se atores comprometidos com a execução de estratégias de geração de renda e acesso a mercados. Segundo os atores, o ponto de partida é a promoção de ações coletivas, associativas e o cooperativismo. Com base em princípios que se aproximam da agroecologia e da produção orgânica, eles privilegiam estratégias e instrumentos de geração de renda a partir de grupos sociais vinculados à agricultura familiar (e às vezes aos médios produtores) em nível local. Procuram privilegiar práticas que podem ser consideradas inovações tecnológicas nas áreas sociais e produtivas, a partir de uma forte presença institucional, em nível territorial.

A intenção de aglutinar nesse grupo a Cooperativa D'IRITUIA (Tenepa); a ONG Extensão Amazônia, a Sedap e Rede Ater (SUD); e a Semagri de Limoeiro do Ajuru (BT) se justifica pelas características aproximadas das suas percepções sobre agroecologia, sobretudo, como mecanismo de ocupação de espaços em mercados. Se expressa uma percepção que valoriza o papel do empreendedorismo de caráter agroecológico na agricultura familiar. Eles traduzem ideias em que consideram a escala territorial mais relevante para execução de suas estratégias e por isso investem em articulações institucionais políticas e de mercado. Contudo, também concebem que é no nível das organizações socioprodutivas locais (municípios, comunidades, ilhas, empreendimentos etc.) que as ações possuem mais possibilidades de serem realizadas. Por isso, privilegiam práticas empreendedoras que impulsionem a efetivação de projetos locais de inclusão socioprodutiva, valorizando a inserção dos produtos da agricultura nos mercados locais e regionais. 
A partir de uma visão empreendedora, as instituições Rede de Ater, Sedap e a ONG Extensão Amazônia, atuam de forma convergente em torno da realização de atividades profissionais que diagnosticam mercados, verificando sua viabilidade e/ou impactos de programas e projetos; realizam capacitação de talentos, com foco no empreendedorismo, lideranças, negociações, gestão, qualidade e manejo sustentável de propriedades. A Semagri de Limoeiro reivindica maior qualificação técnica (inovações tecnológicas) nas atividades da prefeitura municipal, no sentido de profissionalizar as cooperativas locais para alcançar maior qualidade e efetividade nas atividades de extração e comercialização dos produtos da sociobiodiversidade, principalmente quando se trata do açaí e de óleos de espécies nativas, visando, assim, alcançar mercados maiores com os produtos do município.

Com exceção da Cooperativa D' IRITUIA (Tenepa), todos os outros membros desse grupo sempre desempenharam forte presença e atuação nos Codeter de seus respectivos territórios, contribuindo, de alguma forma, para o fortalecimento das estratégias territoriais. Já a Rede de Ater, com vasta capilaridade de atuação por meio das empresas privadas de Ater no Pará, enquadra-se nas orientações técnicas e metodológicas de conformação institucional regidas pela Política Nacional de Ater (PNATER). A Rede concorda que cada empresa associada tem autonomia para desenvolver suas atividades de acordo com seus contratos de trabalho, seja com públicos da agricultura familiar ou da agricultura patronal. De qualquer forma, afirma que os princípios da agroecologia norteiam suas atividades, independentemente de onde atua.

De acordo com os entrevistados, o referencial agroecológico da cooperativa D'IRITUIA preconiza que seus valores são regidos pelo cooperativismo, ao qual se associa ao sentimento coletivo e familiar de produzir e conservar, possibilitando vida digna para seus cooperados. Constituindo-se, provavelmente, como a cooperativa familiar que tem alcançado os mais significativos resultados sociais, organizativos e econômicos do Nordeste Paraense, ela imprime uma dinâmica que assegura mecanismos que favorecem a organização dos agricultores familiares sócios, bem como promove processos permanentes de comercialização de produtos agroecológicos na sociedade local, regional, nacional e mesmo internacional.

Nesse sentido, a prática de uma agricultura de base ecológica, por parte dos agricultores, é fundamental para que se mantenha o padrão de qualidade dos produtos que chegam aos mercados locais e regionais. A valorização dessa produção familiar leva em conta a preservação dos recursos naturais como condição para que se assegurem benefícios permanentes para a saúde humana e animal. Promove-se, nesse ambiente coletivo, os aspectos sociais, culturais, éticos 
e os princípios básicos da cooperação. Esses atores enfatizam a cooperação, o marketing, as redes e as inovações tecnológicas e sociais para a agricultura familiar enquanto estratégia para acessar mercados. Eles promovem a ideia de uma agroecologia capaz de gerar, principalmente, resultados sociais e econômicos na sociedade: a) nos aspectos sociais, primam pelo empoderamento das pessoas nas iniciativas produtivas e de comercialização, a partir de respeitos mútuos nas relações interpessoais; b) no aspecto econômico, apostam na produção agroecológica familiar (coletiva e individual). Nesse sentido, os canais de comercialização são importantes porque viabilizam nichos de mercados locais e regionais, onde quem de fato ganha ao final são os produtores e suas organizações.

\subsection{IDEIAS DE UMA AGROECOLOGIA COMO AÇÃO POLÍTICA (GRUPO 4)}

Esse grupo é composto por ONGs, movimentos sociais e uma rede social: ONG APACC; Fase; STTR de Cametá (BT); MST Estadual; Cepasp (SUD); MMNEPA e a Rede Bragantina (Tenepa). As percepções de agroecologia ora se apresentam da forma mais ampla possível, ora são expressas de maneira pontual e concreta, sem se limitar em disseminar "experiências exitosas" enquanto sinônimo de estágios avançados de agroecologia. Ao mesmo tempo, veem na agroecologia oportunidades para promover a autonomia e o desenvolvimento integrado da agricultura familiar ou camponesa - como categoria específica - no contexto maior do desenvolvimento rural.

Esse conjunto de atores preconiza uma agroecologia que promove práticas de autonomia dos camponeses nos processos de integração aos mercados locais. Eles também estão inseridos em espaços de formação política, no contexto da agroecologia e da agricultura familiar, e estabelecem conexões entre diferentes formas de lutas sociais e a produção de alimentos saudáveis. Além disso, observase que essas entidades possuem bases sociais, ou são capazes de mobilizar muitas pessoas (militantes; membros; instituições membros; associados; discentes etc.), por isso, partem do local (escolas; estabelecimentos agrícolas; grupos produtivos; grupos de interesses comuns) onde, de alguma forma, promovem suas ideias de agroecologia.

Eles também concebem que suas ações locais enfrentam fatores limitantes - do ponto de vista político e administrativo - por conta da ausência de políticas públicas específicas para a agroecologia. As políticas públicas específicas são espaços que devem ser ocupados, como condição para a superação de problemas imediatos. Em nível territorial, eles compreendem 
que a promoção da agroecologia é estrategicamente política, uma vez que ela deve ser, necessariamente, territorializada. Logo, a agroecologia contribui para o enaltecimento da atuação em rede por parte das instituições desse grupo. As feiras agroecológicas, por exemplo, são consideradas um mecanismo eficiente de mobilização dos agricultores, de geração de renda e de caminho viável para envolver a sociedade com o tema da agroecologia.

Nesse grupo, os entrevistados destacam os arranjos institucionais como grandes potenciais para acessar políticas públicas em favor da agricultura familiar e da agroecologia. Além disso, eles afirmam que as ações agroecológicas são consideradas como educação popular, de empoderamento de determinados grupos específicos (jovens, mulheres, ribeirinhos, acampados, assentados) onde, inclusive, já promovem práticas de economia solidária a partir da articulação entre entidades afins.

\section{UMA SÍNTESE DAS IDEIAS}

Nessa parte do trabalho foi realizada uma síntese das quatro ideias (quatro grupos) citadas anteriormente, apresentada agora sob a forma de um gráfico (Figura 2). Busca-se descrever duas variáveis que apareceram discriminantes na análise das percepções de cada ator entrevistado: de um lado, o grau de uma visão integrada da agroecologia; de outro, a escala de ação privilegiada da agroecologia.

Assim, na linha horizontal da Figura 2, parte-se de uma tradução/ interpretação técnico-econômica do referencial da agroecologia (BRUNET, 2013). Expressa-se uma percepção segmentada, produtiva e eminentemente econômica dos sistemas de produção e da comercialização dos produtos da agroecologia. Ela está evoluindo para uma visão integrada da agroecologia, que privilegia os sistemas agroalimentares, evidenciando um enfoque geral/global desses sistemas, inclusive de segurança alimentar.

Igualmente, na vertical, estão as percepções e estratégias dos atores, em termos de escala de intervenção adequada para a promoção da agroecologia e da capacidade de integrar o território nas suas estratégias. O eixo ascendente parte do nível da parcela ou do estabelecimento. No topo do eixo, a promoção da agroecologia é vista como territorializada, por meio de ações articuladas e integradas entre atores de vários tipos e em diferentes escalas.

Dessa forma, é importante notar que a leitura do gráfico vai do canto inferior esquerdo da tabela até o canto superior direito. Eles refletem visões das ideias a partir do local para o territorial, e vice-versa, numa tentativa de executar, mesmo a partir de táticas diferentes, um projeto de desenvolvimento rural baseado em princípios que se aproximem da agroecologia. 
Figura 2 - Visões e traduções da agroecologia nos três territórios - Baixo Tocantins, Nordeste Paraense e Sudeste Paraense

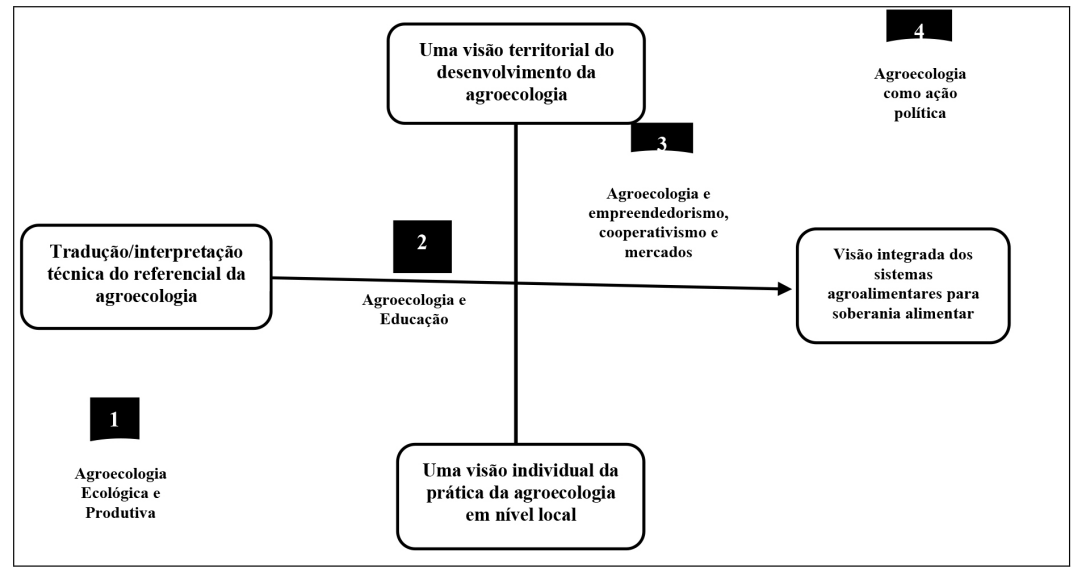

Fonte: elaborada a partir de análise realizada pelos autores (2018).

Como os quatro grupos principais são compostos por instituições da sociedade civil e do poder público, constata-se, de forma geral, o comprometimento de todos os atores entrevistados com a promoção da agroecologia, inclusive as secretarias municipais.

As ideias defendidas pelos atores do grupo 1 (agroecologia ecológica e produtiva) se assemelham pela perspectiva da diversificação produtiva, onde eles manifestam isto através do fortalecimento de processos locais de apoio à implantação e/ou ampliação dos SAFs, ao nível local. Esta lógica produtiva é a característica que melhor identifica esse conjunto de atores em torno de sua visão de agroecologia: Emater (SUD); Codesei (BT); Emater (Tenepa); Fetagri/ GTA (Tenepa); Ufra, campus de Capitão Poço (Tenepa); Embrapa (Tenepa); STTR Limoeiro (BT); e CPT (SUD). Devemos ressaltar que essas características de diversificação produtiva são mais fortemente identificadas no Tenepa, com maioria de atores atuantes em relação aos outros dois territórios, conforme já se tratou anteriormente.

O grupo 2 (agroecologia e educação) concentra um significativo número de instituições, sobretudo oriundas de universidades e escolas de nível médio. Isso não significa que se sobressaia uma agroecologia com perfil eminentemente teórico. Isso pode ser explicado pelas várias experiências de grupos locais, como, por exemplo, tem ocorrido no Baixo Tocantins a implementação de vários projetos locais referentes à educação, financiados por organizações da cooperação internacional, principalmente aquelas vinculadas às ONGs e igrejas. 
Igualmente, a considerável presença de instituições do território institucional do Sudeste Paraense nesse grupo 2 é sintomática.

Novamente, a presença de instituições de ensino, pesquisa e extensão (Unifesspa, EFA e IFPA) pode ser compreendida pela história de construção dos pensamentos agroecológicos, sobretudo a partir da implementação do conjunto de atividades desenvolvidas a partir dos projetos desenvolvidos pela Lasat/ Neaf. Nesse mesmo grupo, no caso do Nordeste Paraense, a construção das ideias agroecológicas - a partir da educação (formal e informal) promovida pela Ecram - deve ser destacada como uma ação afirmativa voltada especificamente para filhos e filhas de agricultores familiares, cuja proposta pedagógica é baseada nos princípios da agroecologia.

No grupo 3 (empreendedorismo, cooperativismo e mercados) é possível perceber determinadas disparidades quanto à sua composição e representatividade territorial: no Sudeste Paraense essas ideias de agroecologia são manifestadas por três atores: ONG Extensão Amazônia, Sedap e Rede Ater; no Nordeste Paraense só foi possível trazer as ideias da Cooperativa D’IRITUIA. Contudo, a atuação e abrangência dessa instituição, em relação aos atores dos outros dois territórios, situa-se em estágios bem avançados, sobretudo no que se refere aos aspectos práticos, gestionários e cooperativos, certamente, resultantes das ideias agroecológicas construídas coletivamente na trajetória da cooperativa. Isso leva a concluir que a força do movimento cooperativista neste território produz um referencial importante que fortalece ainda mais a agroecologia.

O grupo 4 (agroecologia como ação política) é composto majoritariamente por instituições da sociedade civil, com destaque para a atuação de ONGs que há muito tempo atuam, sobretudo, no BT em assessoria a grupos de locais de mulheres, organizações ribeirinhas, associações, cooperativas etc. Com exceção do STTR de Cametá (BT), que possui abrangência municipal, os outros atores possuem atuação territorial e transitam por diversos segmentos da agricultura familiar (ribeirinhos, agricultores convencionais, mulheres, jovens, acampados, assentados, extrativistas etc.). Se analisados em sua amplitude, esses atores sociais estão vinculados às articulações regionais, nacionais e mesmo internacionais semelhantes, que atuam em torno de objetivos próximos acerca de desenvolvimento rural e de agroecologia. No entanto, em nível estadual (e até mesmo, em alguns casos, em nível territorial), elas não estão articuladas entre si.

No conjunto das ideias dos atores, a agroecologia aparece como um conteúdo prático capaz de integrar as estratégias de desenvolvimento, onde se manifestam variadas ações coletivas espontâneas ou articuladas em nível local ou mesmo regionais. Os arranjos institucionais estabelecidos entre instituições do 
poder público e da sociedade civil, ligadas ao campo agroecológico, demonstram que, quando os seus objetivos se aproximam, eles cooperam (como os Codeter e as redes temáticas, por exemplo) demonstrando compromissos com o desenvolvimento da agricultura familiar e, por consequência, com a agroecologia.

Nesse sentido, o critério de escala de atuação de cada ator também é um diferencial nas relações de poder. Isso pode ser percebido nos arranjos estabelecidos entre diferentes atores que convergem em estratégias de ação. Quanto mais atividades de abrangência territorial as instituições (da sociedade civil e do poder público) desenvolvem no território, maior seu poder nas tomadas de decisões.

\section{CONSIDERAÇÕES FINAIS}

Numa perspectiva dos olhares dos atores locais, manifesta-se grande diversidade de ideias agroecológicas nos três territórios citados, emergindo percepções não homogêneas, mas não necessariamente conflitantes. Elas traduzem visões e aferem sentidos a essas percepções locais, dando feição concreta aos princípios e práticas agroecológicas. A visão é fruto dos objetivos de cada instituição, mas também do contexto territorial onde ela atua. Ocorre que, sem a consideração sobre os contextos socioecológicos, o conceito de agroecologia fica desprovido de sentido. Cada manifestação local constrói sua própria forma de concretizar o marco teórico, constituindo sempre novas referências (EMBRAPA, 2006).

Dessa forma, a diversidade das ideias identificadas está relacionada à própria diversidade de atores sociais atuantes, mas também à capacidade e à forma como cada território promoveu as condições possíveis para a viabilização de processos que construíssem diálogos e inter-relações entre as visões de agricultores familiares, instituições públicas e movimentos sociais, em torno do tema da agroecologia.

Essas ideias transitam por diferentes dimensões da agroecologia: a) de caráter ecológico, onde o agroextrativismo se configura como estratégia de conservação dos recursos naturais e geração sustentável de renda; b) socioeducacional, onde os espaços acadêmicos e as escolas por alternância assumem um papel fundamental na promoção de uma agroecologia técnicocientífica; c) na cooperação e empreendedorismo, onde determinadas práticas agroecológicas conseguiram superar barreiras e padrões para acessar mercados; d) e na política, onde se evidenciam práticas agroecológicas de contestação e de organização social para mudanças estruturais na sociedade. 
Essas percepções se concretizam, nos três territórios estudados, a partir de diferentes maneiras coletivas e individuais de se portar em torno do tema da agroecologia. No eixo coletivo, essas ideias se concretizaram por intermédio de ações coletivas dos atores (feiras, redes, eventos, arranjos institucionais, nos Codeter), aglutinando estratégias em nível territorial. No eixo individual (projetos produtivos locais, assessorias, pesquisas, experimentos, feiras locais), esses atores priorizam ações no nível do lote e da comunidade, articulando-os com o nível territorial.

Assim, as relações estabelecidas entre os atores dos diferentes territórios se baseiam, justamente, na sua capacidade de tratar as diferenças entre as ideias sem grandes conflitos e construindo estratégias coletivas em torno do trabalho de desenvolvimento territorial. Essa diversidade se expressa na pluralidade das estratégias de cada ator e, desses, na interação com as dinâmicas territoriais resultantes da aglutinação de visões convergentes, em favor da agricultura familiar e da agroecologia.

\section{REFERÊNCIAS}

ABRAMOVAY, R.; BEDUSCHI FILHO, L. C. Desafios para o desenvolvimento das regiões rurais. Nova Economia, Belo Horizonte, v. 14, n. 3, p. 35-70, set./dez. 2004.

ALTIERI, M. A. Agroecology: the science of sustainable agriculture.

2. ed. Boulder: Westview Press, 2005.

BRANDENBURG, A.; LAMINE, C.; DAROLT, M. Institucionalização do movimento ecológico na agricultura: mercado e reorganização dos atores sociais. Estud. Soc. e Agric., Rio de Janeiro, v. 21, n. 2, p. 221-247, 2013.

BRUNET, B. La mise en acte de l'Agroécologie dans les territoires ruraux du Programme des Territoires de la Citoyenneté (TC)

d'Amazonie Orientale. 2013. 107 f. (Maîtrise em Développement Durable et Aménagement, Développement) - Université Paul-Valéry Montpellier III, Montpellier, 2013.

CAPORAL, F. R.; COSTABEBER, J. A. Agroecologia e extensão rural: contribuições para a promoção do desenvolvimento rural sustentável. Porto Alegre: IICA, 2004. 
COLLADO, Á. C.; GALLAR, D. Agroecologia política: transição social e campesinato. In: CONGRESSO DA ALASRU, 8., 2010, Pernambuco. Anais [...]. Pernambuco: ALASRU, p. 1-23, 2010.

COSTA, F. A. Políticas públicas e dinâmicas agrárias na Amazônia: dos incentivos fiscais ao FNO. In: COSTA, F. A.; TURA, L.R. (org.) Campesinato e Estado na Amazônia: impactos do FNO no Pará. Brasília, DF: Brasília Jurídica: FASE, 2000.

DALLABRIDA, V. R. Desenvolvimento e governança territorial: um ensaio preliminar sobre a necessidade da regulação no processo de gestão do desenvolvimento. Revista Redes, Santa Cruz do Sul, v. 15, n. 3, p. 165-186, set./dez. 2010.

EMBRAPA. Marco referencial em agroecologia. Brasília, DF: Embrapa Informação Tecnológica, p. 70, 2006.

FERNANDES, B. M. Entrando nos territórios do Território. Presidente Prudente: Nera, 2006. Disponível em: http://www2.fct.unesp.br/nera. Acesso em: 24 maio 2018.

GLIESSMAN, S. Agroecologia: processos ecológicos em agricultura sustentável. Porto Alegre: Editora da UFRGS, 2001.

GUSMÁN, E. S. A perspectiva sociológica em agroecologia: uma sistematização de métodos e técnicas. Agroecologia e Desenvolvimento Rural Sustentável, Porto Alegre, v. 3, n. 1, p. 18-28, 2002.

HAESBAERT, R. Territórios alternativos. 2. ed. São Paulo: Contexto, 2006.

MOLINA M. G. Introducción a la agroecología. Valencia: Sociedad Española de Agricultura Ecológica (SEAE), (Série Agroecología y ecología agrária), 2011.

PALIER, B.; SUREL, Y. Les “trois I” et l'analyse de l'État en action.

Revue Française de Science Politique, Paris, vol. 55, p. 7-32, 2005.

PETERSEN, P. Redes de agroecologia como uma alternativa à agricultura industrial. Instituto Humanitas Unisinos, São Leopoldo, 30 maio 2018. Disponível em: http://www.ihu.unisinos.br/579458. Acesso em: 04 jun. 2018. PETERSEN, P.; DAL SOGLIO, F. K.; CAPORAL, F. R. A construção de uma ciência a serviço do campesinato. In: PETERSEN, P. (org.). Agricultura familiar camponesa na construção do futuro. Rio de Janeiro: AS-PTA, p. 85-103, p. 2009. 
PIRAUX, M.; SILVEIRA, L.; DINIZ, P.; DUQUE, G. Transição agroecológica e inovação socioterritorial. Estudos Sociedade e Agricultura, Rio de Janeiro, v. 20, n. 1, p. 5-29, 2012.

RAFFESTIN, C. Por uma geografia do poder. Tradução de Maria Cecília França. São Paulo: Editora Ática, 1993.

SABOURIN, E. Economia solidária no meio rural brasileiro: uma análise a partir da noção de reciprocidade. In: CONGRESO LATINOAMERICANO DE SOCIOLOGÍA RURAL, 9., 2006, Quito. Anais [...]. Quito: Associación Latinoamericana de Sociología Rural (ALASRU), 2006. 1 CD-ROM.

TOLEDO, V. M. Agroecologia é uma revolução epistemológica. Revista Agriculturas, Rio de Janeiro, v. 13. n. 1, p. 42-45, 2016. 